\title{
De novo loss-of-function variants in NSD2 (WHSC1) associate with a subset of Wolf-Hirschhorn syndrome
}

\author{
Elizabeth S. Barrie, ${ }^{1}$ Maria P. Alfaro, ${ }^{1,2}$ Ruthann B. Pfau, ${ }^{1,2}$ Melanie J. Goff, ${ }^{3}$ \\ Kim L. McBride, ${ }^{3,4,5}$ Kandamurugu Manickam, ${ }^{3,5}$ and Erik J. Zmuda ${ }^{1,2}$ \\ ${ }^{1}$ The Institute for Genomic Medicine at Nationwide Children's Hospital, Columbus, Ohio 43215, USA; \\ ${ }^{2}$ Department of Pathology, The Ohio State University College of Medicine, Columbus, Ohio 43210, USA; \\ ${ }^{3}$ Division of Genetic and Genomic Medicine, ${ }^{4}$ Center for Cardiovascular Research, Nationwide Children's \\ Hospital, Columbus, Ohio 43205, USA; ${ }^{5}$ Department of Pediatrics, The Ohio State University College of \\ Medicine, Columbus, Ohio 43210, USA
}

Corresponding author: ezmuda@counsyl.com

(C) 2019 Barrie et al. This article is distributed under the terms of the Creative Commons Attribution-NonCommercial License, which permits reuse and redistribution, except for commercial purposes, provided that the original author and source are credited.

Ontology terms: failure to thrive in infancy; generalized neonatal hypotonia; microcephaly; moderate intrauterine growth retardation; short stature

Published by Cold Spring Harbor Laboratory Press

doi:10.1101/mcs.a004044
Abstract Wolf-Hirschhorn syndrome (WHS) is a rare but recurrent microdeletion syndrome associated with hemizygosity of an interstitial segment of Chromosome 4 (4p16.3). Consistent with historical reports in which overlapping deletions defined a minimal critical region in WHS patients, recent reports from exome sequence analysis have provided further evidence that haploinsufficiency of a specific gene within this critical region, NSD2 (WHSC1), is causal for many features of the syndrome. In this report, we describe three unrelated patients with loss-of-function alterations in NSD2 who presented clinically with WHS features including intrauterine growth retardation and global developmental delay. Two of the three patients also had overlapping features of failure to thrive, short stature, constipation, and hypotonia. This series adds additional cases to expand the phenotypic spectrum of WHS and reports novel NSD2 variants.

\section{CASE PRESENTATION}

Here we report three unrelated patients presenting with intrauterine growth retardation and global developmental delay. Specific measurements of height, weight, and head circumference are provided in Table 1. All have a similar molecular diagnosis from clinical exome sequencing; each patient has either a nonsense or frameshift loss-of-function variant in NSD2. As this gene has been linked to Wolf-Hirschhorn syndrome, we have evaluated their phenotypic features in the context of recent detailed case reports from individuals with similar molecular alterations (Table 2; Boczek et al. 2018; Derar et al. 2018; Lozier et al. 2018).

Patient 1 presented with microcephaly, global developmental delay, hypotonia, and small size. Dysmorphic features included a prominent forehead and broad crus right ear. Pregnancy was complicated by intrauterine growth retardation (IUGR), with low birth weight and subsequent poor growth. Development was slow with first independent steps at 21 mo and first words at 24 mo. The patient did not have a formal autism assessment at the time this manuscript was prepared. He was tested at 13 mo of age using the Cognitive Adaptive Test (CAT)/Clinical Linguistic and Auditory Milestone Scale (CLAMS) tool. The CAT assesses visual motor and problem-solving skills and the CLAMS assesses language skills. His scores fell in the delayed range, with an age equivalent on both scales of 9.5 mo. No seizures were observed. MRI of the brain showed an isolated $4 \mathrm{~mm}$ subependymal gray matter heterotopia along the right lateral ventricular atrial margin. Renal ultrasound was normal. IgA levels at 
Table 1. Patient measurements and demographics

\begin{tabular}{|c|c|c|c|c|c|}
\hline Patient & Height & Weight & Head circumference & Age & Gender \\
\hline 1 & $79.8 \mathrm{~cm}(0.70 \%)(Z=-2.46)$ & $9.3 \mathrm{~kg}(0.06 \%)(Z=-3.26)$ & $43.6 \mathrm{~cm}(<1 \%)(Z=-2.99)$ & $26 \mathrm{mo}$ & Male \\
\hline 2 & $70.5 \mathrm{~cm}(<0.01 \%)(Z=-3.79)$ & $7.2 \mathrm{~kg}(<0.01 \%)(Z=-4.67)$ & $45 \mathrm{~cm}(1.46 \%)(Z=-2.18)$ & $18 \mathrm{mo}$ & Male \\
\hline 3 & $112.5 \mathrm{~cm}(89 \%)(Z=1.20)$ & $25 \mathrm{~kg}(98 \%)(Z=2.14)$ & $49 \mathrm{~cm}(22 \%)(Z=-0.76)$ & $5 \mathrm{yr}$ & Female \\
\hline
\end{tabular}

$24 \mathrm{mo}$ of age were normal at 31 (19-223 $\mathrm{mg} / \mathrm{dL})$. Immune function was not otherwise assessed, but he did not have an excess number of respiratory infections. Complete blood count, liver transaminases, creatinine kinase, IGF1, and TSH were all normal. Genetic evaluation prior to exome sequencing included SNP microarray, fragile $\mathrm{X}$, and $\mathrm{H} 19$ methylation and UPD7 (Russell-Silver syndrome) testing; all were normal.

The phenotype for Patient 2 included failure to thrive, IUGR, short stature, developmental delay, renal hypoplasia, chronic kidney disease, and pancreatic insufficiency. Pregnancy was complicated by IUGR and a scheduled Cesarean section was performed at $37 \mathrm{wk}+2 \mathrm{~d}$ for continued poor growth. Patient was small for gestational age and admitted to the NICU for respiratory distress syndrome including pneumothorax as well as nutritional support. After discharge from the NICU, the patient was readmitted for acid reflux and kidney issues. The patient had ongoing failure to thrive (including height and weight). Development was slow with babbling around 8-12 mo and one word at $18 \mathrm{mo}$. The patient began walking around $18 \mathrm{mo}$. A formal autism assessment had not been performed at the time this manuscript was prepared. At $32 \mathrm{mo}$, he was given a developmental assessment using the CAT/ CLAMS tool described above. He was found to be significantly delayed by both measures with an age equivalent of 21 mo. Dysmorphic features included wide bridge of nose and loose skin on hands and feet. The patient had a normal brain ultrasound, and no seizure

\begin{tabular}{|c|c|c|c|c|c|c|c|}
\hline WHS clinical features & Patient 1 & Patient 2 & Patient 3 & $\begin{array}{c}\text { Boczek et al. } \\
2018\end{array}$ & $\begin{array}{l}\text { Lozier et al. } \\
2018\end{array}$ & $\begin{array}{l}\text { Derar et al. } 2018 \\
\text { Patient } 1\end{array}$ & $\begin{array}{l}\text { Derar et al. } 2018 \\
\quad \text { Patient } 2\end{array}$ \\
\hline Age at assessment & $26 \mathrm{mo}$ & $18 \mathrm{mo}$ & $5 \mathrm{yr}$ & $3 \mathrm{yr}$ & $16 \mathrm{mo}$ & $5 \mathrm{yr}$ & $34 \mathrm{mo}$ \\
\hline Characteristic facies & + & + & + & + & + & + & + \\
\hline Developmental delay & + & + & + & + & + & + & + \\
\hline Poor weight gain & + & + & - & + & + & + & + \\
\hline Hypotonia & + & $+($ mild $)$ & $+($ mild $)$ & + & + & + & + \\
\hline $\begin{array}{l}\text { Apparent intellectual } \\
\text { disability }\end{array}$ & NR & + & + & NR & + & + & + \\
\hline $\begin{array}{l}\text { Intrauterine growth } \\
\text { restriction (IUGR) }\end{array}$ & + & + & + & + & - & + & + \\
\hline Microcephaly & + & + & - & + & + & + & + \\
\hline Postnatal growth deficiency & + & + & - & + & + & + & + \\
\hline Short stature & + & + & - & + & + & + & + \\
\hline \multicolumn{8}{|l|}{ Nonclassical WHS features } \\
\hline $\begin{array}{l}\text { Autism spectrum disorder } \\
\text { (ASD) }\end{array}$ & NR & NR & + & NR & NR & NR & NR \\
\hline Constipation & + & - & + & + & NR & NR & NR \\
\hline Pancreatic insufficiency & NR & + & NR & NR & NR & NR & NR \\
\hline Bilateral renal hypoplasia & - & + & $N R$ & NR & - & NR & NR \\
\hline
\end{tabular}

An indication of whether each patient was positive (+), negative $(-)$ for each feature is provided as well as if the feature was not reported (NR). 
activity had been noted. Renal ultrasounds showed echogenic kidneys suggestive of parenchymal renal disease but no hydronephrosis or scarring. At the time of manuscript preparation, the patient met criteria for stage 2 chronic kidney disease. Blood pressure was well controlled on enalapril. IgA levels were normal at 35 (reference range 19-223 mg/dL). Complete blood counts were essentially normal. Genetic evaluation prior to exome sequencing included microarray and fragile $X$ syndrome testing; both were normal.

Patient 3 presented with global developmental delay and autism spectrum disorder (ASD). IUGR was noted at 20 wk and growth remained delayed, leading to a Cesarean section at 38 wk. Feeding issues began early with small volume intake and extended feeding times. She walked independently around $29 \mathrm{mo}$ and said her first word around $30 \mathrm{mo}$. At age 4 she began using sentences. She was diagnosed with ASD at age $4.5 \mathrm{yr}$ following the administration of neurocognitive testing (Autism Diagnostic Observation Schedule [ADOS]: Module 2, Mullen Scales of Early Learning, Developmental Profile-Third Edition [DP-3] and Autism Spectrum Rating Scales [ASRS]). She also exhibited delays in both receptive and expressive language functioning at the level of a 34-mo-old (Mullen T-scores 25 and 24 , respectively). She began gaining more weight around age 4 , and by age 5 was classified as obese. At the time of assessment at age 5 , the patient did not have microcephaly. The patient wears glasses for myopia. Genetic evaluation prior to exome sequencing included microarray and fragile $\mathrm{X}$ syndrome testing; both were normal.

\section{TECHNICAL ANALYSIS}

Genomic DNA isolated from peripheral blood of the patient and both parents was used for exome sequencing. Libraries were prepared and enriched for targets of interest using the SureSelect ${ }^{X T}$ Human all exon V6 kit (Agilent). Libraries were sequenced using the Illumina HiSeq platform. The mean depth on probe for each sample was $\geq 127$, and $\geq 96.6 \%$ of the probe base pairs were covered at $>20 \times$. The reads were aligned to the reference sequence (GRCh37/hg19 Feb 2009) and variants identified using the GenomeNext pipeline (v2.5.2, 3.0.0 or 3.1.2). The resulting variant call format (VCF) file from GenomeNext was uploaded to Genelnsight (Sunquest) for the purpose of annotation and filtering. Sanger sequencing was used to confirm the de novo nature of the variants, whereas a custom Agena genotyping panel was used to affirm maternity and paternity of the samples submitted with each proband.

\section{VARIANT INTERPRETATION}

The variants were interpreted using the American College of Medical Genetics (ACMG) guidelines (Richards et al. 2015). These variants all encode a premature stop of translation predicted to cause nonsense-mediated decay and haploinsufficiency in a gene in which loss of function is a known mechanism of disease (Table 3). All variants were confirmed to be de novo, with maternity and paternity confirmed. Finally, all variants were absent from the Genome Aggregation Database (gnomAD; r2.0.2). These alterations all met the same ACMG guidelines for classification as pathogenic variants (ACMG: PVS1, PS2, PM2).

For patients 1 and 3, no additional variants were included on the clinical exome report. For patient 2, two variants of undetermined clinical relevance to the patient's phenotype were reported. The first was a paternally inherited missense change, Chr 19:46271987A>G; c.116T>C; p.(Leu39Ser), in SIX5 (NM_175875.4) that was classified as a variant of uncertain significance (VUS) as it fulfilled none of the ACMG criteria. This gene is associated with branchiootorenal syndrome 2 (OMIM: 610896), and the variant was evaluated based on the patient's renal hypoplasia. The second variant reported for patient 2 was a maternally 


\begin{tabular}{|c|c|c|c|c|c|c|c|c|c|c|}
\hline Patient & Gene & Chromosome & HGVS DNA & HGVS cDNA & HGVS protein & Variant type & Predicted effect & $\begin{array}{c}\text { dbSNP/ } \\
\text { dbVar ID }\end{array}$ & Genotype & $\begin{array}{c}\text { Exon } \\
\text { \# (of 24) }\end{array}$ \\
\hline 1 & NSD2 & 4 & $1906053 G>A$ & c. $708 \mathrm{G}>\mathrm{A}$ & p.Trp236Ter & Substitution & Nonsense & N/A & Heterozygous & 5 \\
\hline 2 & NSD2 & 4 & 1936884dupG & c.1569dupG & p.Lys524GlufsTer17 & Duplication & Frameshift & N/A & Heterozygous & 9 \\
\hline 3 & NSD2 & 4 & $1918630 C>T$ & c. $793 \mathrm{C}>\mathrm{T}$ & p.Gln265Ter & Substitution & Nonsense & N/A & Heterozygous & 6 \\
\hline
\end{tabular}

inherited missense change, Chr 5:147207678T>C; c.101A>G; p.(Asn34Ser), in SPINK1 (NM_003122.4) that was classified as a VUS based on the following ACMG criteria: PS4, PM3, PP5, BS3, and BP4. The gene is associated with multiple pancreatic phenotypes and was evaluated because of the patient's phenotype of pancreatic insufficiency

\section{SUMMARY}

The NSD2 gene encodes the nuclear receptor-binding set domain protein 2 that acts as a histone methyltransferase. It maps to the Wolf-Hirschhorn syndrome (WHS, OMIM: 194190) critical region and is also referred to as the WHSC1 (WHS candidate 1) gene. Recent publications describe patients with apparently de novo, loss-of-function variants in this gene who present with clinical features resembling WHS, including developmental delay, postnatal growth deficiency, intellectual disability, feeding difficulties, hypotonia, microcephaly, and characteristic facies including a high forehead and wide nasal bridge (Boczek et al. 2018; Derar et al. 2018; Lozier et al. 2018; Zollino and Doronzio 2018). These features were also found in patients in the current case series. In contrast to patients with WHS, those with NSD2 loss-of-function variants have not presented with seizures to date (this cohort included).

In the current case series, only one patient underwent a formal autism assessment. Patient 3 was diagnosed with ASD, a finding not noted in the most recent case reports. However, large-scale analysis of autism cohorts did detect two patients with de novo truncating variants in NSD2, suggesting autism may be an additional feature of WHS spectrum (De Rubeis et al. 2014; Wang et al. 2016; Yuen et al. 2017). As we only present a single case with ASD in our series, we cannot conclude that the ASD features are due to the NSD2 variant. Longitudinal, follow-up studies on all patients in the recent case reports would be of interest to determine if they develop ASD.

For the family of Patient 1, this genetic diagnosis had novel implications for management of the patient's symptoms. It was determined that because this is a genetic condition, he will not likely benefit from growth hormone treatment or attempts to increase his caloric load. His growth will not follow typical patterns and therefore his height and weight will now be plotted on the WHS growth charts to better assess his progress (Antonius et al. 2008). This recommendation is likely to be beneficial for all patients with loss-of-function variants in NSD2.

Overall, there is growing evidence for de novo loss-of-function variants in the NSD2 gene to be pathogenic and contributing to a subset of WHS patients lacking classic phenotypic features.

\section{ADDITIONAL INFORMATION}

\section{Database Deposition and Access}

The variants and their interpretations have been submitted to the ClinVar database (https://www.ncbi.nlm.nih.gov/clinvar/) for variant IDs 599448, 599447, and 599449. The 
Competing Interest Statement

The authors have declared no competing interest.

\section{Referees}

Marcella Zollino

Anonymous

Received February 11, 2019; accepted in revised form May 6, 2019. submission accession numbers are SCV000864314.1, SCV000864312.1, and SCV00086 4315.1 for Patients 1, 2, and 3, respectively. Patient consent did not allow for deposition of raw sequencing data.

\section{Ethics Statement}

Written consent for clinical testing was provided by the parents of Patients 1-3. The research is under a protocol approved by the Institutional Review Board at Nationwide Children's Hospital (IRB18-00662).

\section{Author Contributions}

All authors contributed to manuscript preparation/review and scientific discussion.

\section{Acknowledgments}

We thank the patients and their families for their participation.

\section{Funding}

There are no funding sources to report.

\section{REFERENCES}

Antonius T, Draaisma J, Levtchenko E, Knoers N, Renier W, van Ravenswaaij C. 2008. Growth charts for WolfHirschhorn syndrome (0-4 years of age). Eur J Pediatr 167: 807-810. doi:10.1007/s00431-007-0595-8

Boczek NJ, Lahner CA, Nguyen TM, Ferber MJ, Hasadsri L, Thorland EC, Niu Z, Gavrilova RH. 2018. Developmental delay and failure to thrive associated with a loss-of-function variant in WHSC1 (NSD2). Am J Med Genet A 176: 2798-2802. doi:10.1002/ajmg.a.40498

Derar N, Al-Hassnan ZN, Al-Owain M, Monies D, Abouelhoda M, Meyer BF, Moghrabi N, Alkuraya FS. 2018. De novo truncating variants in WHSC1 recapitulate the Wolf-Hirschhorn (4p16.3 microdeletion) syndrome phenotype. Genet Med 21: 185-188. doi:10.1038/s41436-018-0014-8

De Rubeis S, He X, Goldberg AP, Poultney CS, Samocha K, Cicek AE, Kou Y, Liu L, Fromer M, Walker S, et al. 2014. Synaptic, transcriptional and chromatin genes disrupted in autism. Nature 515: 209-215. doi:10 .1038/nature13772

Lozier ER, Konovalov FA, Kanivets IV, Pyankov DV, Koshkin PA, Baleva LS, Sipyagina AE, Yakusheva EN, Kuchina AE, Korostelev SA. 2018. De novo nonsense mutation in WHSC1 (NSD2) in patient with intellectual disability and dysmorphic features. J Hum Genet 63: 919-922. doi:10.1038/s10038-018-0464-5

Richards S, Aziz N, Bale S, Bick D, Das S, Gastier-Foster J, Grody WW, Hegde M, Lyon E, Spector E, et al. 2015. Standards and guidelines for the interpretation of sequence variants: a joint consensus recommendation of the American College of Medical Genetics and Genomics and the Association for Molecular Pathology. Genet Med 17: 405-424. doi:10.1038/gim.2015.30

Wang T, Guo H, Xiong B, Stessman HA, Wu H, Coe BP, Turner TN, Liu Y, Zhao W, Hoekzema K, et al. 2016. De novo genic mutations among a Chinese autism spectrum disorder cohort. Nat Commun 7: 13316. doi:10 $.1038 /$ ncomms 13316

Yuen RKC, Merico D, Bookman M, Howe LJ, Thiruvahindrapuram B, Patel RV, Whitney J, Deflaux N, Bingham J, Wang Z, et al. 2017. Whole genome sequencing resource identifies 18 new candidate genes for autism spectrum disorder. Nat Neurosci 20: 602-611. doi:10.1038/nn.4524

Zollino M, Doronzio PN. 2018. Dissecting the Wolf-Hirschhorn syndrome phenotype: WHSC1 is a neurodevelopmental gene contributing to growth delay, intellectual disability, and to the facial dysmorphism. J Hum Genet 63: 859-861. doi:10.1038/s10038-018-0476-1 


\title{
COLD SPRING HARBOR Molecular Case Studies
}

\section{De novo loss-of-function variants in NSD2 (WHSC1) associate with a subset of Wolf -Hirschhorn syndrome}

\author{
Elizabeth S. Barrie, Maria P. Alfaro, Ruthann B. Pfau, et al.
}

Cold Spring Harb Mol Case Stud 2019, 5: a004044 originally published online June 6, 2019 Access the most recent version at doi: $10.1101 / \mathrm{mcs} .0004044$

\begin{tabular}{|c|c|}
\hline License & $\begin{array}{l}\text { This article is distributed under the terms of the Creative Commons } \\
\text { Attribution-NonCommercial License, which permits reuse and redistribution, except } \\
\text { for commercial purposes, provided that the original author and source are credited. }\end{array}$ \\
\hline $\begin{array}{l}\text { Email Alerting } \\
\text { Service }\end{array}$ & $\begin{array}{l}\text { Receive free email alerts when new articles cite this article - sign up in the box at the } \\
\text { top right corner of the article or click here. }\end{array}$ \\
\hline
\end{tabular}

